\title{
A TOOL FOR DESIGN EXPLORATION AND POWER OPTIMIZATION OF CMOS RF CIRCUITS BLOCKS
}

\author{
Leonardo Barboni, Rafaella Fiorelli, Fernando Silveira
}

Instituto de Ingeniería Eléctrica -Universidad de la República, Uruguay. Email: [lbarboni, fiorelli, silveira]@fing.edu.uy

\begin{abstract}
A tool that explores the design space of basic RF circuit blocks is presented. The tool takes advantage of the application of an MOS transistor model continuous in all inversion levels (weak to strong inversion). The performance of the circuit is analyzed in the $I_{D}-g_{m} / I_{D}$ plane. The tool shows the existence of a inversion level that provides an optimum in the power consumption for a given gain and frequency. Examples are presented showing how comparison of the performance of different technologies or evaluation of the effect of parasitic elements can be easily done. The tool is applied to the design of a power amplifier and a VCO at $910 \mathrm{MHz}$ in $0.35 \mu \mathrm{m}$ CMOS technology. The tools estimations are checked against simulations using BSIM3v3, showing very good agreement. Additionally, preliminary experimental results are presented.
\end{abstract}

\section{INTRODUCTION}

Nowadays, the development of low-cost, low-power radiofrequency (RF) devices grows up rapidly, and those systems are characterized by short range links (usually below $100 \mathrm{~m}$ ) and reduced power consumption (since the devices are powered with batteries).It is known that optimum power consumption of analog circuits can be reached in the moderate inversion region [1], where is obtained a good trade-off between a high $\mathrm{g}_{\mathrm{m}} / \mathrm{I}_{\mathrm{D}}$ and a not too large transistor size and hence reduced parasitic capacitances values. Traditionally the operation at this optimum was restricted to low frequency applications, since the transconductance values required for operation at RF implied currents that, in order to operate in moderate inversion, lead to enormous transistor sizes. However, the scaling of devices changes this scenario as it is shown in this work. This idea, the possibility of exploiting operation in weak and moderate inversion for RF in scaled technologies, has also been advanced in $[2,3,4]$.

However, as far as we know, there is no published work where a tool for analyzing the trade-offs and possible optimum solution has been presented. In this work this improvement is applied to design power amplifiers and voltage controlled oscillators (VCO). It will be presented a software tool which can be used either to design amplifiers, obtaining an optimum design and showing the trade off between amplifier's gain and power consumption, or to evaluate the performance of a particular technology at a desired frequency. With this tool it has been checked the good performance of a $0.35 \mu \mathrm{m}$ technology at $910 \mathrm{MHz}$ and it has been designed a $\mathrm{VCO}$ and a power amplifier of $40 \mathrm{~V} / \mathrm{V}$ gain and $5.5 \mathrm{~mA}$ current consumption.

This work was supported by the MOSIS MEP/Research program and the PDT (1293/OC-UR, 17/17) grant of Conicyt, Uruguay.

\section{MODEL AND ALGORITHM}

\section{A. Modeling approach}

Firstly, the approach applied for modeling the MOS transistor in small signal operation and the amplifier building blocks is presented. A physical, compact MOS transistor model, continuous from weak to strong inversion (ACM [5]) was selected. As discussed later, a five intrinsic capacitances, quasistatic model was deemed sufficient for analyzing the circuits in the desired regions and frequencies.

The basic amplifier structures considered are modeled by quadripoles, as it is shown in Fig.1, in order to represent different configurations and loads.

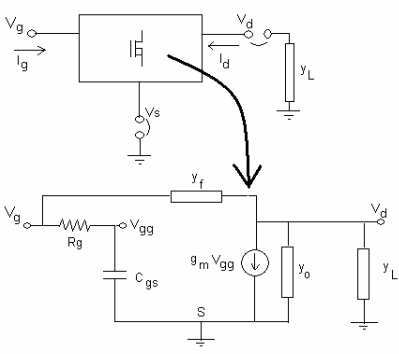

Figure 1: Transistor modeled as a quadripole and basic internal small signal model

The two port relations of the quadripole in Fig. 1 can be written as:

$$
\begin{aligned}
& i_{d}=y_{d d} v_{d s}+y_{d g} v_{g s} \\
& i_{g}=y_{g d} v_{d s}+y_{g g} v_{g s}
\end{aligned}
$$

Assuming that the MOS transistor operates in saturation and in the quasi-static regime, the transadmittances shown in Eq.2 are automatically computed.

This transadmittances include intrinsic capacitances $\left(\mathrm{C}_{\mathrm{db}}, \mathrm{C}_{\mathrm{gs}}\right.$, $\mathrm{C}_{\mathrm{gb}}, \mathrm{C}_{\mathrm{sb}}, \mathrm{C}_{\mathrm{dg}}$ ) and extrinsic capacitances (overlap and junction capacitances). Assuming the transistor in saturation, $\mathrm{C}_{\mathrm{db}}$ and $\mathrm{C}_{\mathrm{dg}}$ are equal to zero. The gain of the stage $\mathrm{A}$ is given by:

$$
A=\frac{v_{d s}}{v_{g s}}=\frac{-y_{d g}}{y_{d d}+y_{L}}
$$

The model that has been presented is a quasi-static model (QS). However, the limitation of the QS model is known at high frequency where the non-quasi-static (NQS) effects have influence. That is why it is important to have an estimation of the frequency which limits the zones of QS and NQS operation. This limit has been fixed at $0.1 \cdot \mathrm{f}_{\mathrm{T}}$ (where $\mathrm{f}_{\mathrm{T}}$ is the unitary gain frequency of the transistor) as it is proposed in [6][7]: 


$$
f_{Q S \max } \approx \frac{f_{T}}{10}=\frac{0.1 g_{m}}{2 \pi\left(C_{g s}+C_{g b}+C_{g d}\right)}
$$

Working below this limit also assures that is not necessary to use the complete model of the nine intrinsic capacitances and transcapacitances of the device [6].

Another effect that can limit the performance of the transistor MOS at high frequency is the carrier velocity saturation; an effect that is noticeable in very strong inversion. But, as in this work it is shown that it is possible and convenient to work in moderate inversion, in the following this effect is not considered. In case of working in very strong inversion $\left(\mathrm{g}_{\mathrm{m}} / \mathrm{I}_{\mathrm{D}}\right.$ less than $3 \ldots 41 / \mathrm{V}$ ), velocity saturation can modify the results shown.

\section{B. Design Space Exploration Algorithm}

The proposed algorithm for designing RF amplifier blocks considers the design space defined by the DC bias current $\mathrm{I}_{\mathrm{D}}$ of the active transistor and its $g_{m} / I_{D}$ ratio; parameters that define the transistor aspect ratio (W/L) [1]. The transistor length is always the minimum allowed by the technology in order to maximize the high frequency performance by decreasing parasitic capacitances. In this design space the current consumption was considered for a given voltage gain at a given frequency.

The algorithm is summarized as follows: the design space is covered by a grid of couples $\left(I_{D}, g_{m} / I_{D}\right)$. For each of these couples the gain $\mathrm{A}=\mathrm{A}\left(\mathrm{I}_{\mathrm{D}}, \mathrm{g}_{\mathrm{m}} / \mathrm{I}_{\mathrm{D}}\right)$, width $\mathrm{W}=\mathrm{W}\left(\mathrm{I}_{\mathrm{D}}, \mathrm{g}_{\mathrm{m}} / \mathrm{I}_{\mathrm{D}}\right)$ and quasi-static boundary $B=B\left(I_{D}, g_{m} / I_{D}\right)$ are obtained.

Having explored this design space, as it is shown in the example of the following section, for a given gain, there is a $\mathrm{g}_{\mathrm{m}} / \mathrm{I}_{\mathrm{D}}$ value that results in an optimum of consumption. This optimum lies in moderate inversion for usual gain values.

This algorithm adds the evaluation of the harmonic distortion of the stage, so that the design space can be limited to those areas that comply with a given distortion target.

\section{RESULTS AND DISCUSSIONS}

In this example, a one-stage amplifier with load capacitance $\mathrm{C}_{\mathrm{L}}$ and a feedback resistance $R_{F}$ is presented, as it is shown in Fig.2.

The a priori design values are: $\mathrm{C}_{\mathrm{L}}=0.5 \mathrm{pF}, \mathrm{R}_{\mathrm{F}}=5 \mathrm{k} \Omega, \mathrm{f}_{0}=$ $910 \mathrm{MHz} \mathrm{W}_{\mathrm{MP}}=20 \mu \mathrm{m}, \mathrm{L}_{\mathrm{MP}, \mathrm{M} 1}=0.35 \mu \mathrm{m}$. In the first part of the example the gate resistance $\mathrm{R}_{\mathrm{g}}$ is neglected. Later, it is studied the degradation of the previous results if the $\mathrm{R}_{\mathrm{g}}$ corresponding to a non-interdigitized layout is considered.

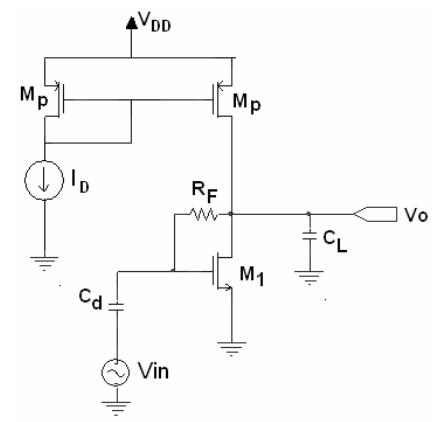

Figure 2: Example circuit.

Neglecting $R_{g}$ and considering that the desired gain is $2 \mathrm{~V} / \mathrm{V}$, the algorithm generates the gain curve of Fig.3 (circle markers), where the optimum is marked with an arrow. It is also shown the curve of optima (points of minimum consumption for a given gain, square markers); thus if it is desired to work optimally for a chosen gain, the current $I_{D}$ and the $g_{m} / I_{D}$ ratio (and therefore the transistor width) are fixed.

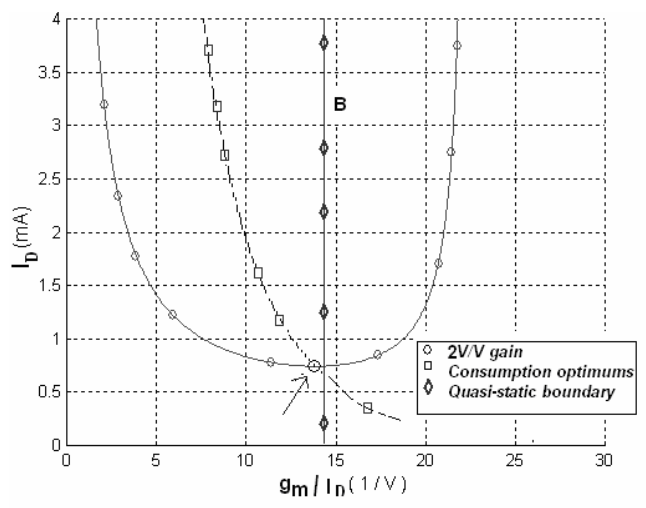

Figure 3: Result of example. Marked with circular markers is the 2V/V gain curve, with square markers is the optima of consumption and with rhomboid markers (B curve) is the quasi-static boundary @ 910MHz.

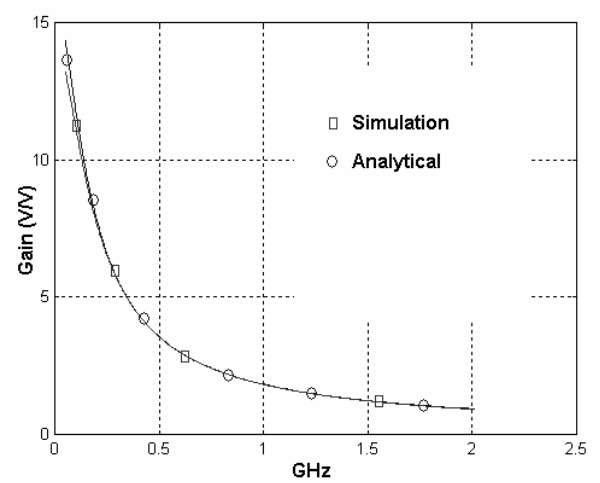

Figure 4: Frequency response calculated and simulated, neglecting Rg.

Fig.3 also shows the quasi static boundary limit B for this technology (rhomboid markers), where, given a working frequency $f_{0}$, the maximum $g_{m} / I_{D}$ is fixed independent of $I_{D}$. In the optimal point the width of $\mathrm{M}_{1}$ is $223 \mu \mathrm{m}, \mathrm{I}_{\mathrm{D}}$ is $0.75 \mathrm{~mA}$, and $\mathrm{g}_{\mathrm{m}} / \mathrm{I}_{\mathrm{D}}$ is almost 14 . The algorithm results have been contrasted with simulation results using BSIM3v3, and, as it is shown in Fig.4, a good correlation has been found.

To show the potential of the proposed tool is terms of evaluating design trade-offs, it is studied how the gate resistance degrades the performance of the amplifier designed previously, if proper care is not taken at the layout.

The algorithm adds $\mathrm{R}_{\text {geff }}=\mathrm{R}_{\mathrm{g}} / 3$, considering a non interdigitized layout for the transistor $\mathrm{M}_{1}[6]$, with a resistance per square of the gate material of $8.6 \mathrm{k} \Omega / \mathrm{sq}$. From Fig. 5 it is clear than the new optimum occurs at a higher current consumption that the previous one (marked by an arrow in the figure). Despite the gate resistance effect is extensively known, it is interesting to see the effect on the consumption at a given gain. 


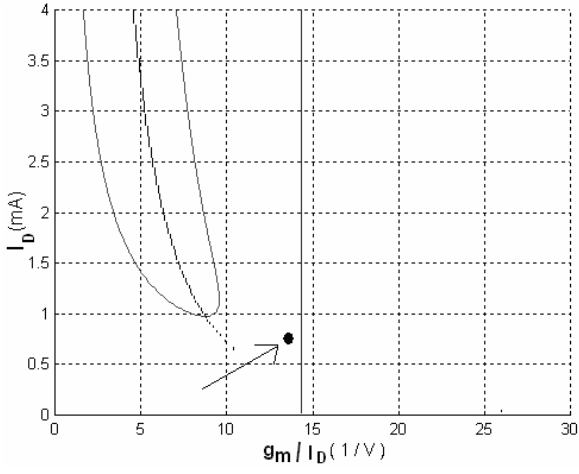

Figure 5: Gain curve of $2 \mathrm{~V} / \mathrm{V}$ of example when the effect of $R_{g}$ of a non interdigitized layout is considered. The point marked by the arrow shows the location of the minimum consumption point determined in Fig. 3 for a negligible $\mathrm{R}_{\mathrm{g}}$.

Figure 6 shows the tool user interface which is a fully interactive plot. The designer can move a cursor on the $\mathrm{I}_{\mathrm{D}}-\mathrm{g}_{\mathrm{m}} / \mathrm{I}_{\mathrm{D}}$ plane and each time the designer selects a point, several characteristics such as bias point, level of inversion, gain, power gain, $\mathrm{HD}_{2}, \mathrm{IM}_{3}$ and other circuit parameters are automatically computed as a function of the selected $\mathrm{I}_{\mathrm{D}}-\mathrm{g}_{\mathrm{m}} / \mathrm{I}_{\mathrm{D}}$ couple and shown in the left part of the screen.

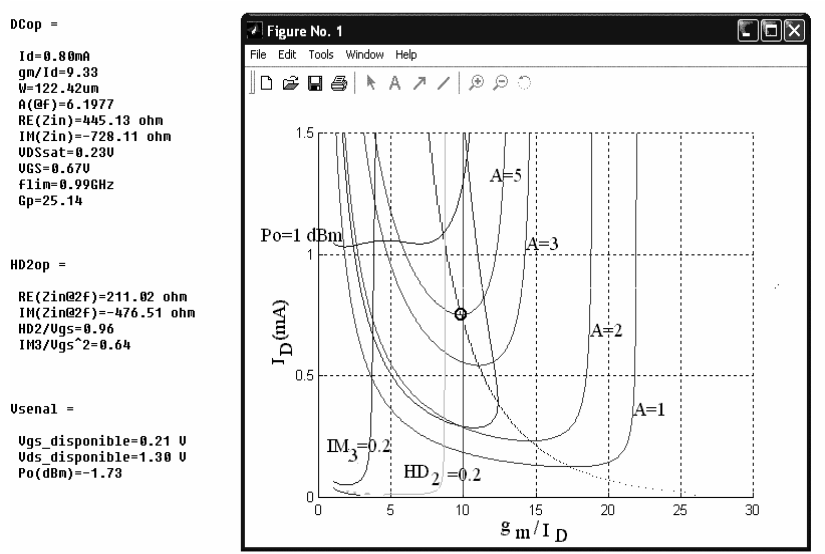

Figure 6: Tool user interface

\section{IMPLEMENTATION}

Using the described methodology, the amplifier shown in Fig.7 has been designed. The final design parameters are:

Table I: Data of the designed amplifier.

\begin{tabular}{|c|c|c|c|c|}
\hline & $M_{1}$ & $\mathbf{M}_{2}$ & $M_{3}$ & $M_{P}$ \\
\hline $\mathbf{W}(\mu \mathrm{m})$ & 60 & 60 & 80 & 200 \\
\hline $\mathrm{I}_{\mathrm{D}}(\mathrm{mA})$ & 0.5 & 0.5 & 1.5 & 2.54 \\
\hline
\end{tabular}

Current mirrors: $\mathrm{Me}_{0}, \mathrm{Me}_{1}, \mathrm{Me}_{2}: \mathrm{W}=20 \mu \mathrm{m} \mathrm{Me}_{3}: \mathrm{W}=60 \mu \mathrm{m}$

Feedback DC bias: R1=R2=15 k $\Omega, C 2=1 \mathrm{pF}$

Power given to the load $\mathrm{R}_{\mathrm{L}}: 2 \mathrm{dBm}$

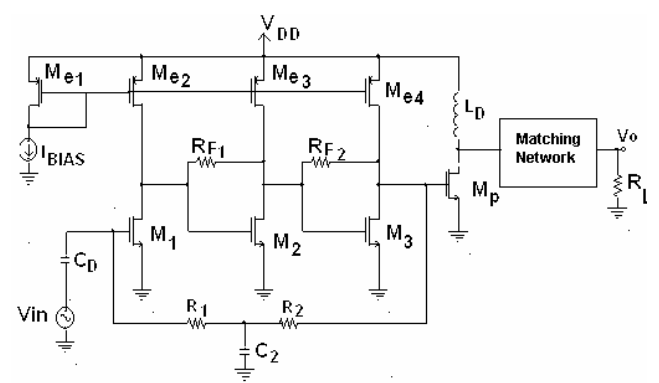

Figure 7: Amplifier implemented in $0.35 \mu \mathrm{m}$ technology with $40 \mathrm{~V} / \mathrm{V}$ gain at $910 \mathrm{MHz}$.

\section{MEASUREMENT RESULTS}

A chip including this amplifier was fabricated. Unfortunately, a layout error was introduced during the final adjustments in the overall chip layout. This error made that the DC feedback, that sets the overall amplifier bias point, was non functional. Anyhow, in order to test the amplifier, the bias was set in open loop, which made it much more inaccurate and unstable.

Nevertheless, by testing several bias points and performing extensive simulations, it has been possible to select a bias point where it was possible to measure the performance of the circuit. In Table II are shown the results of the measurements, when $\mathrm{V}_{\mathrm{DD}}$ is $2.3 \mathrm{~V}, \mathrm{~V}_{\text {bias }}$ is $0.83 \mathrm{~V}$ and $\mathrm{I}_{\mathrm{D}}$ is $0.5 \mathrm{~mA}$

Table II: Measured and simulated characteristics.

\begin{tabular}{|c|c|c|}
\hline Characteristics & Measured & Simulation \\
\hline $\mathrm{I}_{\mathrm{DD}}($ at 0 power delivered) & $3.21 \mathrm{~mA}$ & $3.22 \mathrm{~mA}$ \\
\hline$P_{\text {out }}()^{\prime}$ & $-8.9 \mathrm{dBm}$ & $-5.7 \mathrm{dBm}$ \\
\hline Harmonic Distortion:HD ${ }_{2}$ & $-26.5 \mathrm{~dB}$ & $-22.0 \mathrm{~dB}$ \\
\hline Voltage gain & $8.9 \mathrm{~V} / \mathrm{V}$ & $12.7 \mathrm{~V} / \mathrm{V}$ \\
\hline
\end{tabular}

These results confirm the operation of the preamplifier stages $\left(\mathrm{M}_{1}, \mathrm{M}_{2}\right.$ and $\mathrm{M}_{3}$ in Fig. 6) at $910 \mathrm{MHz}$ while biased in moderate inversion as calculated. New designs have been fabricated and will be tested soon.

\section{DESIGN OF A-G G $_{M}$ LC CROSS-COUPLED VCO IN $0.35 \mu M$ CMOS TECHNOLOGY}

In this section the methodology and design of a $910 \mathrm{MHz}$ crosscoupled $-\mathrm{G}_{\mathrm{m}}$ LC VCO [8] in $0.35 \mu \mathrm{m}$ CMOS standard technology with on-chip inductors [9] is presented (see Fig.8) Also it is shown how the tool previously presented is used to validate the use of a quasi-static model to design this VCO.

Being $G_{m}$ the equivalent transconductance of the nMOS crosscoupled transisor block (with $\mathrm{G}_{\mathrm{m}} \cong \mathrm{g}_{\mathrm{m}, \mathrm{i}}, \mathrm{g}_{\mathrm{m}, \mathrm{i}}$ the transconductances of transistors $\left.\mathrm{M}_{\mathrm{i}}, \mathrm{i}=1,2\right), \mathrm{g}_{\text {tank }}$ the equivalent tank conductance (assumed to be approximately $2 \cdot \mathrm{g}_{\text {inductor }}$ ) and $\alpha$ the oscillation factor (a design criterion usually equal to 3 ), then the VCO oscillation condition is $\mathrm{Gm}=\alpha \cdot \mathrm{g}_{\text {tank }}$. If $\mathrm{g}_{\mathrm{m}} / \mathrm{I}_{\mathrm{D}}$ of $\mathrm{M}_{\mathrm{i}}$ is increased while $\alpha$ and the inductance electrical characteristics are known, then $g_{m, M O S}$ is fixed and $I_{D}$ decreases (with 
$\mathrm{I}_{\mathrm{D}}=\mathrm{I}_{\mathrm{bia}} / 2$ ). However, the minimum possible value of $\mathrm{I}_{\mathrm{D}}$ is limited by the maximum oscillator phase noise value specified [10][11], as it increases when $\mathrm{I}_{\mathrm{D}}$ drops. It is also limited by the parasitic capacitances of $\mathrm{M}_{\mathrm{i}}, \mathrm{i}=1,2$, since an increment in $\mathrm{g}_{\mathrm{m}} / \mathrm{I}_{\mathrm{D}}$ produces an increment in the transistor's width. The last also restricts the oscillation frequency and diminish the tuning range.

Considering the previous discussion, the VCO design methodology proposed is presented in the scheme of Fig.9. Given an inductor value $L$ and a oscillation frequency $\mathrm{f}_{0}$, the inductor dimensions and its parameters are calculated ( $g_{\text {inductor }}$ and quality factor among others). With them, $g_{m} / I_{D}$ and $\alpha$, it is found $\mathrm{I}_{\mathrm{D}}$. Using the transistor's characteristic curves $\left(\mathrm{g}_{\mathrm{m}} / \mathrm{I}_{\mathrm{D}}\right.$ vs. $\left.\mathrm{I}_{\mathrm{D}} /(\mathrm{W} / \mathrm{L})\right)$, the width $\mathrm{W}$ of $\mathrm{M}_{\mathrm{i}}$ and the varactor capacitance $\mathrm{C}_{\mathrm{var}}$ are obtained.

In this work the emphasis has been laid on decreasing power consumption without a great detriment on phase noise. The transistors were dimensioned to work in moderate inversion $\left(\mathrm{g}_{\mathrm{m}} / \mathrm{I}_{\mathrm{D}} \cong 11, \mathrm{~W}=450 \mu \mathrm{m}\right)$ with a bias current of $2.8 \mathrm{~mA}$ and the power consumption is $8.4 \mathrm{~mW}$ and a phase noise of $-107 \mathrm{dBc} / \mathrm{Hz} @ 600 \mathrm{kHz}$. In this design it has been assumed the quasi-static operation of the circuit because the quasi-static boundary of this transistor at $910 \mathrm{MHz}$ has been checked with the tool previously described (the boundary is around $\left.\mathrm{g}_{\mathrm{m}} / \mathrm{I}_{\mathrm{D}}=14\right)$.

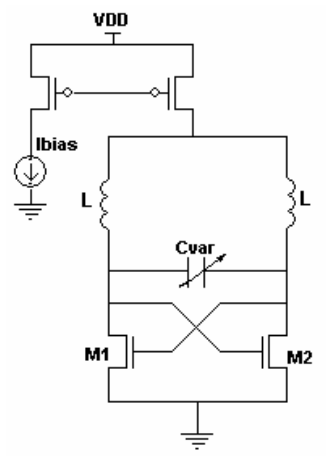

Figure 8: Cross-coupled -Gm LC VCO.

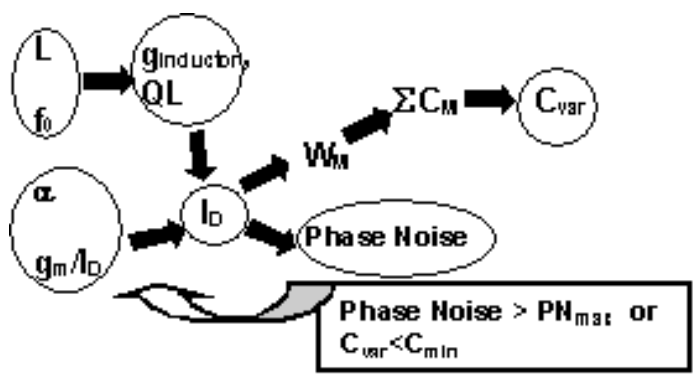

Figure 9: Proposed VCO design methodology considering the phase noise and power consumption specifications.

\section{VII-CONCLUSION}

In this work it has been presented a flexible tool to help in the design of low power RF blocks. It has also been shown the existence of an optimum inversion level which gives the minimum power consumption for a given gain, or equivalently, the maximum gain for a given consumption. This optimum inversion level appears in different types of amplifiers and in varied technologies. Finally it has been shown the feasibility of working, with $0.35 \mu \mathrm{m}$ technologies at $910 \mathrm{MHz}$, in moderate inversion, which gives a better compromise between speed and consumption.

\section{REFERENCES}

[1] F.Silveira, D. Flandre, P.G.A. Jespers, "A gm/ID Based Methodology for the Design of CMOS Analog Circuits and its Application to the Synthesis of a Silicon-on-Insulator Micropower OTA", IEEE Journal of Solid State Circuits, Vol. 31, No. 9, Sept. 1996, pp. $1314-1319$

[2] A.S.Porret, T Melly, D.Python, C.C.Enz, E.A.Vittoz. "An Ultralow - Power UHF Transceiver Integrated in a Standard Digital CMOS Process: Architecture and Receiver". IEEE Journal of Solid-Sate Circuit VOL 36 ,NO 3 ,March 2001 ,pp. 452-466.

[3] J. Ramos et al, "90nm RF CMOS technology for low-power 900MHz applications", ESSDERC 2004, pp. 329-332.

[4] V. Varotto, O. Gouveira-Filho, "Design of RF CMOS Low Noise Amplifiers Using a Current Based MOSFET Model", Proceedings of 17th Symposium on Integrated Circuits and Systems Design. Porto de Galinhas, v. 1, p. 82-87, September 2004.

[5] A.A.Cunha, M.C.Schneider, C.Galup-Montoro "An MOS Transistor Model for Analog Circuit Design". IEEE Journal of SolidSate Circuit VOL 33, NO 10,October 1998, pp.1510-1519.

[6] Yannis Tsividis, Operation and Modeling of the Mos Transistor, McGraw Hill 1999 2nd.ed. - ISBN 0-07- 065523-5.

[7] Allen F.L, Ping K. Ko and Mansum Chan "Determining the Onset Frequency of Nonquasiestatic Effects of the MOSFET in AC Simulation". IEEE Electron Device Letters, Vol. 23, No 1 January 2002 pp37-39

[8] Ali Hajimiri, Thomas Lee, "Design issues in CMOS differential LC oscillators", IEEE Journal of Solid StateCircuits, Vol 34 No 5, May 1999, pp 717-724.

[9] C.P. Yue, C. Ryu, J. Lau, T.H. Lee and S.S. Wong "A Physical Model for Planar Spiral Inductors on Silicon," in 1996 International Electron Devices Meeting Technical Digest, pp. 155-158, Dec. 1996.

[10] J.Raler, A.Abidi, "Physical Processes of Phase Noise in Differential LC Oscillators", IEEE 2000 Custom Integrated Circuits Conference.

[11] Ali Hajimiri, "Trade-offs in oscillator phase noise", chapter of "Trade off in analog circuit design", Kluwer, 2002 